RAFAEL FECURY NOGUEIRA

\title{
PRONÚNCIA: VALORAÇÃ̃ DA PROVA E LIMITES À MOTIVAÇÃO
}

\author{
DissertaÇão de MeStrado
}

Orientador: Professor Associado Maurício Zanoide de Moraes

FACULDADE DE DIREITO DA UNIVERSIDADE DE SÃO PAULO SÃO PAULO 


\section{RESUMO}

O presente trabalho analisa a valoração da prova na decisão de pronúncia e os limites à sua motivação, realizando-se, inicialmente, um estudo sobre a origem dessa decisão com base em decisões de ordenamentos jurídicos passados.

A regência legal da pronúncia é estudada para a compreensão de sua definição, requisitos, cognição e função que exerce no procedimento do Júri.

Em relação à valoração da prova, objeto central do presente trabalho, estabelece-se um critério de decisão com base nos standards de prova da autoria ou da participação. A motivação é estudada para a verificação do funcionamento dos limites impostos pela lei a ela.

Palavras-chave: Pronúncia, Tribunal do Júri, função, valoração da prova, motivação. 


\section{ABSTRACT}

This study examines the valuation of proof in the indictment decision and the justification, and where, inictially a study about the origin of this decision based on past legal decisions.

The rulership to indictment is studied to understand its definition, requirements, cognition and the function that performs the procedure of the Jury.

Regarding the evidence of proof, the central object of the present study, we establish a decision based on the standards of proof to authorship. The justification is studied to verify the functioning of the limits imposed by law to it.

Key-words: Indictment, Jury, function, valuation of proof, justification. 


\section{INTRODUÇÃO}

O Tribunal do Júri é a instituição jurídica que mais aguça a curiosidade popular e a que proporciona intensos debates na doutrina, sobretudo, processual penal, culminando com severas opiniões contrárias ${ }^{1}$ e claras opiniões favoráveis ${ }^{2}$ a esse peculiar Tribunal existente no Brasil alçado à categoria de direito e garantia fundamental constitucional (artigo $5^{\circ}$, XXXVIII).

Como características primordiais do Tribunal do Júri, têm-se o julgamento pelas pessoas do povo e a ausência de motivação das decisões tomadas pelos jurados, mantendo, a rigor, as características originais do modelo de Júri clássico.

Isso torna o Tribunal do Júri ainda mais excêntrico na medida em que o seu procedimento é o único com tais caracteres.

Nesse cenário procedimental do Tribunal do Júri, exsurge outra característica apenas verificável nesse procedimento especial: a decisão de pronúncia, que exerce redobrada importância jurídico-política por ser a decisão que conclui pelo envio do feito a julgamento popular.

Com efeito, na decisão de pronúncia se realiza a valoração da prova validamente produzida no curso da instrução preliminar do procedimento do Júri para determinar o prosseguimento do feito à fase subsequente do julgamento final caso satisfeitos os seus requisitos legais.

Evidenciada, de plano, a relevância da pronúncia no procedimento do Júri, vê-se que, para grande parte dos posicionamentos jurisprudenciais, a preconizada competência constitucional do Júri para o julgamento dos crimes dolosos contra a vida serve como o próprio (e único) fundamento para o perfazimento da pronúncia e consequente envio do

\footnotetext{
1 - Um dos principais críticos e opositores do Júri, sem dúvida, é FREDERICO MARQUES, José. A Instituição do Júri. São Paulo: Saraiva, 1963, pp. 5/6.

2 - Favorável ao julgamento pelo povo, tem-se TORNAGHI, Helio. Instituições de Processo Penal. $2^{\mathrm{a}}$ ed. São Paulo: Saraiva, 1977, v. I, pp. 50/51; e AZEVEDO, Noé. As garantias da liberdade individual em face das novas tendencias penaes. São Paulo: Revista dos Tribunais, 1936, pp. 202/204.
} 
acusado para o julgamento pelo Júri popular de modo a não subtrair a apreciação final do caso a quem detém a competência constitucional para tanto.

Ademais, há uma preocupação legal, doutrinária e jurisprudencial de que os fundamentos utilizados pelo magistrado na justificação da decisão de pronúncia não influenciem os jurados propiciando um julgamento sem que o(s) argumento(s) do juiz de direito afetem a compreensão dos jurados sobre o caso a ser julgado por eles.

De outro lado, a pronúncia, pela relevância que exerce no procedimento do Júri, deve possuir fundamentação suficiente a demonstrar de maneira satisfatória o preenchimento dos requisitos legais exigidos.

A decisão de pronúncia, portanto, convive com um dilema inafastável: ao mesmo tempo em que ela deve ser fundamentada, como toda a decisão judicial, deve também, de outro lado, ter a sua fundamentação contida, maneirada, sóbria, para que os jurados não sejam influenciados pela decisão do magistrado.

Ademais, outro dilema envolvendo a pronúncia chama a atenção ao determinar o Código de Processo Penal que a mesma não poderá ser utilizada como argumento de autoridade pelas partes no momento dos debates em plenário para preservar os jurados de influências da decisão do magistrado. No entanto, segundo o mesmo Código, antes da instrução em plenário da sessão do Júri, os jurados receberão cópias da decisão de pronúncia, facultando-se, portanto, à sua leitura aos jurados.

Tratam-se, portanto, de aspectos controvertidos do procedimento dos crimes de competência do Tribunal do Júri e, por essas razões, o presente trabalho se propõe a analisar o tema da valoração da pronúncia e os limites impostos à sua motivação.

Para essa empreitada, vislumbrando-se a necessidade de se dar "um passo atrás" na análise percuciente da pronúncia para melhor compreendê-la, iniciou-se o presente trabalho com o estudo histórico de várias decisões em diversos ordenamentos do passado para se buscar a origem remota da decisão atualmente conhecida como pronúncia.

Nesse particular, analisaram-se as características, requisitos e funções das decisões que analisam a admissibilidade da acusação no antigo direito romano do período comicial, no direito inglês da Baixa Idade Média, no direito lusitano dos séculos XV a XVII, 
passando pelo momento em que entrou em vigor a primeira codificação processual penal do Brasil - o Código de Processo Criminal de primeira instância de 1832 - até a vigência dos Códigos de Processo Penal estaduais no começo do século XX, possibilitando-se uma visualização abrangente do modo como as decisões que deram origem à pronúncia se comportaram até se transformar na decisão que se tem hoje no Brasil.

A partir da compreensão histórica da pronúncia, passou-se a analisar o seu regramento legal e dogmático (atual) com o estudo do procedimento do Júri como garantia fundamental e sua destinação, da definição da pronúncia, de sua natureza jurídica, de seus requisitos legais, da cognição exercida na pronúncia, além de uma breve análise da impronúncia e da sentença de absolvição sumária, finalizando-se com a função exercida pela pronúncia no procedimento do Júri.

Com a delimitação histórica, legal e dogmática da pronúncia, passou-se a analisar criticamente o tema da prova no contexto dessa decisão partindo da evolução histórica dos sistemas de valoração da prova penal até se chegar ao atual estágio do sistema do "livre convencimento motivado" ou da "persuasão racional". Nesse caminho passaram o direito romano, o sistema das Ordálias ou "juízos de Deus", o sistema da "prova legal” ou "tarifada", o sistema da "íntima convicção" e o da "prova legal negativa".

Com a estabilização do atual sistema de valoração da prova denominado de livre convencimento motivado, teceram-se considerações sobre um possível novo sistema de valoração da prova conhecido como "valoração racional da prova" com a consequente análise dos standards de prova como critério legal de justificação das decisões penais, buscando-se uma delimitação para a suficiência da prova da autoria exigida para a decisão de pronúncia desde uma perspectiva dos standards probatórios ou modelos de constatação.

Delimitada, histórica e dogmaticamente, a pronúncia, bem como estabelecidos os critérios de suficiência para a valoração da prova da autoria dessa decisão, chega-se, então, ao momento de análise dos limites à motivação dessa decisão.

Essa análise se inicia pela compreensão da motivação das decisões penais como garantia política e jurídica no ordenamento processual brasileiro, passando pelo estudo da motivação da decisão de pronúncia e o risco de excesso de linguagem e a exigência de moderação de linguagem do juiz como óbice à influência subjetiva dos jurados. 
Verificou-se, ainda, o problema da dúvida no momento decisório com a análise dos critérios de decisão para os casos de dúvida do julgador: o in dubio pro reo e o in dubio pro societate.

O presente trabalho culmina com a análise do funcionamento do in dubio pro societate na decisão de pronúncia, buscando-se verificar a legitimidade e validade do in dubio pro societate como critério de decisão para os casos de dúvida do julgador sobre a confirmação da admissibilidade da acusação.

Por fim, o escopo do presente trabalho é o de propor uma releitura da decisão de pronúncia e, consequentemente, do procedimento do Tribunal do Júri no que concerne à acusação e sua progressão, buscando-se, assim, a estabilização de critérios puramente técnicos para essa decisão e um repensar crítico sobre o tema da valoração da prova e dos limites impostos à motivação da pronúncia. 


\section{CONCLUSÕES}

A origem remota da decisão de pronúncia atualmente conhecida no Brasil está no contexto do procedimento das quaestiones perpetuae do antigo período acusatório do processo penal romano existente entre os séculos II e I a.C, o qual previa uma decisão chamada de nomen recipere, nomen deferre ou nomen receptio.

A nomen recipere, assim como a pronúncia, realizava um segundo juízo de admissibilidade da acusação, além de se assemelhar à pronúncia quanto ao conteúdo acusatório, ao momento em que eram apreciadas, ao magistrado que a apreciava e, por fim, quanto à função que exercia no procedimento de enviar o acusado a julgamento popular. A nomen recipere e a pronúncia se aproximam externa e internamente.

Após o procedimento das quaestiones perpetuae, verifica-se um juízo de admissibilidade da acusação no modelo clássico do júri inglês, o qual, com toda a influência que gerou no modelo de júri em diversos ordenamentos jurídicos, é o responsável pela moderna sistematização da fase de admissibilidade da acusação, em um claro aperfeiçoamento do modelo esculpido pelas quaestiones perpetuae.

Essa sistematização mais apurada do juízo de admissibilidade da acusação se dá com a instituição do grand jury inglês originada no reinado de Henrique II com as Cortes de Clarendon no ano de 1.164.

O juízo sobre o grand jury se revestiu de caráter de garantia do procedimento do júri inglês, rompendo-se com o modelo anterior que o vislumbrava como órgão de investigação e acusação, a partir do momento em que estabeleceu um corpo de jurados composto de 12 (doze) homens livres que realizavam a análise da "filtragem" de todo o conteúdo acusatório para determinar ou não o prosseguimento do feito a julgamento final pelo petty jury,

A origem da pronúncia nas Ordenações do Reino de Portugal se dá com as Ordenações Philipinas, ao prever a pronúncia como a sentença do juiz que declarava o réu suspeito do delito quando provado o crime e descoberta a sua autoria com base na análise do corpo de deito e dos indícios de autoria. 
A pronúncia das Ordenações Philipinas, embora não remetesse a causa a julgamento, realizava um juízo (prévio) de admissibilidade da acusação se aproximando do conteúdo e requisitos da atual decisão de pronúncia desde o seu ingresso no Brasil.

O ingresso do juízo de admissibilidade da acusação no Brasil se dá com a própria Constituição Política do Império de 1824, que a previu e lhe conferiu caracteres gerais. Após ela, o Decreto de 17 de abril de 1824, a Lei de 15 de outubro de 1827 e a Lei de 20 de setembro de 1830 construíram o caminho para a pronúncia tipicamente brasileira até a promulgação da primeira legislação processual penal nacional, o Código de Processo Criminal de 1832.

O Código de 1832 previu conteúdo da pronúncia da mesma forma como atualmente concebido. Contudo, a análise desse conteúdo foi transportada para o momento do recebimento da denúncia após a formação da culpa a ser proferida por um Juiz de Paz, os quais tinham funções também policiais. Para a procedência da denúncia deveria haver a plena comprovação do delito e indícios veementes de quem fosse o delinquente.

No procedimento dos crimes de responsabilidade dos empregados públicos, a pronúncia ocorria após o recebimento da denúncia, prevendo-se a chamada sustentação da pronúncia a ser feita pelo juiz de direito com a submissão aos jurados do Jury de accusação, com atribuição de analisar a correção da pronúncia proferida.

O primeiro Conselho de Jurados ou Júri de Acusação era composto de 23 cidadãos para analisar a remessa ou não do caso a julgamento pelo Júri de Sentença, devendo verificar a existência de suficiente esclarecimento sobre o crime e seu autor.

O Júri de Acusação foi extinto pela Lei n. 261 de 1841, afastando-se a pronúncia dos modelos inglês de português para se aproximar da sua concepção atual no Brasil. A partir desse momento, a pronúncia passa a cumprir a função exercida pelo Júri de Acusação.

Com o advento dos Códigos de Processo Penal estaduais entre o final do século XIX e começo do século XX, mantém-se a estrutura já conhecida da pronúncia, não se verificando alterações de relevo, ao menos nos Códigos do Rio de Janeiro, do Rio Grande do Sul, da Bahia e do Pará, em relação ao regramento da pronúncia das derradeiras leis e decretos federais do final do século XIX. 
A partir da concepção constitucional do Tribunal do Júri como garantia fundamental prevista no artigo $5^{\circ}$, XXXVIII, da Constituição Federal, tem-se como destinatário tanto o jurado, assegurando-se a sua participação direta na administração da justiça, quanto o acusado, para que possa concretizar a plenitude de defesa e conter eventuais excessos acusatórios.

O procedimento do Tribunal do Júri, por sua vez, é uma garantia destinada ao cidadão a ele submetido para obstar o avanço de acusações infundadas ou buscar a sua absolvição sumária.

Atualmente, a decisão de pronúncia está prevista no artigo 413, do Código de Processo Penal, tratando-se de decisão que encerra a fase instrutória e instaura o julgamento final no procedimento do Tribunal do Júri. É o limiar entre a primeira fase do procedimento e o seu julgamento.

A pronúncia, assim, é a decisão que encerra a fase de instrução preliminar do procedimento do Júri verificando o preenchimento dos seus requisitos legais.

Os requisitos da pronúncia estão previstos no artigo 413, caput, e no seu $\S 1^{\mathrm{a}}$, do Código de Processo Penal, exigindo-se a prova da materialidade do fato e da existência de indícios suficientes de autoria, os quais significam, em termos probabilísticos, certeza da existência do fato e probabilidade da autoria ou da participação do acusado.

A cognição a ser exercida na pronúncia não pode ser limitada, mas sim a sua fundamentação que deve se ater ao disposto no $\S 1^{\circ}$, do artigo 413, do Código de Processo Penal, resumindo-se o juiz a expor apenas a indicação da existência do fato e da probabilidade da autoria ou da participação, pois, o controle fático e jurídico da acusação no procedimento do Júri deve ser feito pela decisão que confirma ou não a admissibilidade da acusação devendo a sua cognição ser extensa e profunda suficientemente a demonstrar o cumprimento dos requisitos previstos no artigo 413, do Código.

A impronúncia corresponde ao reverso da pronúncia, a rigor, a sua face oposta, por consistir em decisão residual em relação à pronúncia, pois só terá lugar em caso de não convencimento do juiz para a pronúncia. 
A impronúncia, a despeito de concluir pela improcedência da acusação, não faz coisa julgada, sendo possível que se instaure novo processo pelo mesmo fato caso $\operatorname{surja}(\mathrm{m})$ nova(s) prova(s), devendo-se entender como prova nova uma fonte de prova até então desconhecida pelas partes, caso contrário, haveria sério risco à segurança jurídica a reinstauração da causa com base em fonte de prova já conhecida.

Ademais, a ausência de definição jurídica da situação processual do impronunciado é questão delicada e sem fundamento jurídico, devendo-se a impronúncia, a partir da Lei n. 11.689/08, que a confirmou como sentença, fazer coisa julgada material e vedar nova persecução pelos mesmos fatos antes impronunciados.

A pronúncia não pode mais ser vista de forma simplista como fazem os Tribunais, como fase corriqueira do procedimento do Júri, mas deve encarnar a função que o seu procedimento lhe impõe de efetivamente confirmar a admissibilidade da acusação.

Nesse sentido, a pronúncia deve possuir a função de confirmar a admissibilidade da acusação analisando a consistência da acusação inicialmente proposta e a sua evolução no curso da instrução para que nela apenas passem as acusações suficientemente sustentadas e que conseguiram demonstrar, até o momento da pronúncia, a existência do fato e a probabilidade da autoria ou da participação.

Na evolução dos sistemas de valoração da prova, tem-se como o primeiro e sistema de valoração da prova, o chamado julgamento das ordálias ou dos juízos de deus, o qual, embora não houvesse propriamente a apreciação de elementos probatórios, ligando-se muito mais à questões de fé e crença, pode-se considerar o julgamento das ordálias como o primeiro sistema ou método probatório por conferir uma forma (mal) organizada e contínua para a conclusão final sobre os fatos, ainda que precária e absurda.

Buscando aperfeiçoar o sistema de valoração da prova, estabeleceu-se um critério para sanar a ausência de racionalidade do sistema das ordálias por meio do sistema da "prova legal" ou da "prova tarifada", no qual, o valor de cada meio de prova estava ex ante previsto na lei vinculando o julgador àquela determinada tarifação legal, fixando, assim, a própria lei a quantidade e qualidade da prova que deveria alicerçar determinada decisão. 
Embora esse sistema retirasse toda a liberdade de apreciação do juiz, na época em que fora elaborado (Idade Média), tratou-se de um avanço em relação ao sistema antecedente das ordálias, pois, trouxe um critério bem definido para a valoração da prova.

Posteriormente, o sistema da "prova legal" ruiu em face do contínuo uso da tortura como meio de prova para a obtenção da confissão, considerada a "rainha das provas" e necessária para a obtenção plena da condenação, falecendo a sua racionalidade primitiva.

Surge, então, o método da "íntima convicção" na apreciação da prova como reprovação ao que havia se tornado o sistema inquisitório da "prova legal" e como consequência direta das profundas alterações proporcionadas pela Revolução Francesa, que impôs um novo modo de pensar o Estado, o cidadão, a relação entre ambos e, consequentemente, tudo o que se relacionasse com o sistema processual penal.

Sendo um sistema que dispensa a motivação das decisões, logo se viu a impossibilidade de controle do juízo de fato sobre essas decisões, dando margem a discricionariedades e a arbítrios por parte dos juízes na apreciação das provas.

Essa crise existencial do sistema da "íntima convicção" contribuiu para que Napoleão, após tomar o poder, influenciasse as discussões no Conselho de Estado francês para a criação do sistema processual penal misto, em que abarca referências dos sistemas inquisitório e acusatório, mantendo-se uma estrutura que melhor servisse ao Imperador.

Buscando-se remediar os abusos perpetrados pelo sistema misto e pela íntima convicção, surge na Alemanha a teoria da "prova legal negativa", preconizando que se deve impor à liberdade de convencimento do juiz certos limites, como, a permissão ao juiz condenar apenas quando a prova estivesse de acordo com a exigência legal nos termos do antigo sistema da "prova legal". E, de outra banda, conferia a íntima convicção ao juiz no caso de absolvição ou quando não tivesse inteira e profunda convicção da prática delituosa, aproximando-se do que se tem como o sistema do "livre convencimento motivado".

O método da "prova legal negativa" não se sustentou na Alemanha do século XIX, dando lugar a um novo modelo que seguiu a escala evolutiva dos sistemas de valoração da prova penal em busca de um modelo que conferisse moderada liberdade ao julgador impondo a ele que baseasse as suas conclusões com as provas dos autos, evitando-se o arbítrio judicial ao exigir a comprovação probatória de todas as conclusões tomadas. 
Com efeito, a partir da adoção do "livre convencimento motivado", seja qual for a decisão - absolvição ou condenação - deverá o juiz motivar a sua decisão com base na(s) prova(s) dos autos.

É o modelo atualmente previsto no Brasil, nos artigos 155 e 381, III, do Código de Processo Penal, e em quase todo o mundo ocidental.

Buscando conferir ainda mais racionalidade à análise da prova, a chamada "valoração racional da prova" visa propor critérios que possam assegurar às partes meios para conhecer exatamente como foi exercida a liberdade de convicção do julgador, permitindo, consequentemente, o controle e a consequente cassação dos desvios motivacionais.

A "valoração racional da prova", além de buscar reduzir o subjetivismo judicial na decisão, objetiva minimizar o número de erros sobre os fatos provados, manifestando-se como instrumento capaz de medir a probabilidade da ocorrência do fato em causa. A principal forma de minimizar os erros se dá com a fixação de graus de probabilidade de uma determinada hipótese, estipulando-se o nível de probabilidade que se exige para se ter uma hipótese como devidamente provada.

O determinado grau de probabilidade mencionado para a verificação da corroboração da hipótese pode ser extraído a partir de um determinado modelo de constatação, quantidade de prova (quantum de prova) ou standards de prova, os quais surgem como mecanismo de distribuição desses erros entre as partes.

Três são os standards de prova mais comumente aplicados, dos quais dois deles são os standards padrão - a prova além da dúvida razoável e a preponderância da prova -, e o terceiro como um standard intermediário entre os dois primeiros - a prova clara $e$ convincente.

A prova da autoria ou da participação exigida para a pronúncia é o grande dilema probatória dessa decisão, residindo na dificuldade de delimitação do grau de probabilidade de autoria exigido para ela.

Os indícios suficientes de autoria ou de participação, na atual conjuntura da prova penal e do procedimento do júri, não significam propriamente a exigência de prova 
indiciária para a pronúncia, mas indicam um quantum de prova exigido para ela, a saber, a probabilidade da autoria, a ser vista diante em detalhes.

O critério de delimitação do standard de prova deve se dar conforme as diversas decisões penais e as respectivas funções que exercem no procedimento.

Para a decisão de pronúncia, vislumbrando-se o espaço entre os standards da preponderância da prova e o da prova além da dúvida razoável, i.e., entre a mera probabilidade e a prova plena, respectivamente, e diante de toda a prova produzida no curso da instrução preliminar do procedimento do Júri, deve-se estabelecer a alta probabilidade para a prova da autoria na pronúncia semelhante ao standard da prova clara e convincente.

Em relação à limitação da pronúncia, é preferível a sua fundamentação suficiente, ainda que com o risco de influenciar o jurado, mas que exerça a função de analisar a consistência e evolução da acusação filtrando um maior número de acusações, do que uma decisão limitada para não influenciar os jurados permitindo que passem pelo filtro da pronúncia acusações indevidas, inconsistentes ou insuficientes.

No quadrante da existência do fato e da alta probabilidade da autoria ou da participação, pode (e deve) o magistrado abordar e justificar a pronúncia da maneira mais percuciente possível, abstendo-se, contudo, de fazer menção a qualquer termo que extrapole esse conteúdo legal, como a afirmação de que o réu é culpado ou de expor as razões que o levaram a não acolher uma excludente.

O critério de decisão a prevalecer em caso de dúvida no momento do judicium accusationis do procedimento do Júri não pode mais ser o in dubio pro societate, o qual deve ser excluído das decisões dos magistrados brasileiros para dar lugar ao único critério de decisão realmente legítimo e válido - o in dubio pro reo -, o qual deve incidir, também, em toda a extensão do processo penal. 


\section{BIBLIOGRAFIA}

ALBERNAZ, Flavio Boechat. O princípio da motivação das decisões do Conselho de sentença. Revista Brasileira de Ciências Criminais. São Paulo: Revista dos Tribunais, ano 5, n. 19, 1997.

ALMEIDA JUNIOR, João Mendes de. O processo criminal brazileiro. $3^{\mathrm{a}}$ ed. Rio de Janeiro: Typ Baptista de Souza, 1920, v. I e II.

ANDRIOLI, Virgilio. Appunti di procedura penale. Napoli: E. Jovene, 1965.

AQUINO, Álvaro Antônio Sagulo Borges de. A função garantidora da pronúncia. Rio de Janeiro: Lumen Juris, 2004.

ARANGIO-RUIZ, Vincenzo. Storia del Diritto Romano. 7. ed. Napoli: Jovene, 2006.

AZEVEDO, Noé. As garantias da liberdade individual em face das novas tendencias penaes. São Paulo: Revista dos Tribunais, 1936.

BACH, Lydia Marie. Developpement du jury en Anglaterre. Geneve: S.N, 1915.

BADARÓ, Gustavo Henrique. Direito Processual Penal. 2a ed. Rio de Janeiro: Elsevier, 2009, tomo II.

Ônus da prova no processo penal. São Paulo: Revista dos Tribunais, 2003.

BALL, V.C. The moment of truth: probability theory and standards of proof. Vanderbilt Law Review, n. 14, 807, 1960-1961.

BALTAZAR JUNIOR, José Paulo. Standards probatórios no processo penal. Revista Jurídica, v. 363, Porto Alegre, 2008.

BARGI, Alfredo. Cultura del processo e concezione della prova. Teoria e prassi della prova: profili processual-filosofici. (Org. BARGI, Alfredo; GAITO, Alfredo; SAGNOTTI, Simona C.). Torino: Utet, 2009. 
BAUMAN, Richard A. Crime and punishment in ancient Rome. London: Routledge, 1996.

BENTO, Patrícia Stucchi. Pronúncia: enfoque constitucional. São Paulo: Quartier Latin, 2008.

BINDER, Alberto M. Introdução ao direito processual penal. Tradução de Fernando Zani. Rio de Janeiro: Lumen Juris, 2003.

BISCARDI, Arnaldo. Aspetti del fenomeno processuale nell' esperienza giuridica romana. $2^{\mathrm{a}}$ ed. Milano: Cisalpino-Goliardica, 1978.

BITENCOURT, Cezar Roberto. Tratado de direito penal: parte geral. $9^{\mathrm{a}}$ ed. São Paulo: Saraiva, 2004, v. I.

BITENCOURT, Edgard de Moura. A Instituição do Júri. São Paulo: Saraiva, 1939.

BLACKSTONE, William. Commentaires sur les lois anglaises. Trad. de N. M. Paris: Chompré, 1822, v. VI.

CAFFERATA NORES, José Ignácio; HAIRABEDIÁN, Maximiliano. La prueba en el proceso penal. $6^{\text {a }}$ ed. Buenos Aires: Lexis Nexis, 2008.

CARNELUTTI, Francesco. La prueba civil. 2. ed. Tradução de Niceto Alcalá-Zamora y Castillo. Buenos Aires: Depalma, 2000.

CARVAlHO, Luis Gustavo Grandinetti Castanho de. Processo penal e Constituição: princípios constitucionais do processo penal. $3^{\text {a }}$ ed. Rio de Janeiro: Lumen. Juris, 2004.

CHOUKR, Fauzi Hassan. Júri: Reformas, continuísmos e perspectivas práticas. Rio de Janeiro: Lumen Juris, 2009.

- Código de Processo Penal: Comentários consolidados e crítica jurisprudencial. $2^{\mathrm{a}}$ ed. Rio de Janeiro: Lumen Juris, 2007.

CLERMONT, Kevin M; e SHERWIN, Emily. A comparative view of standards of proof. The American Journal of comparative law. 50 Am. J. Comp. L. 243, 2002. 
COELHO, Walter. Prova indiciária em matéria criminal. Porto Alegre: Sergio Antonio Fabris Editor/Fundação Escola Superior do Ministério Público do Rio Grande do Sul, 1996.

CORDERO, Franco. Procedimiento penal. Bogotá: Temis, 2000, t. I e II.

CRUZ, Rogério Schietti Machado. A proibição de dupla persecução penal (ne bis in idem): limites no direito brasileiro. São Paulo: Faculdade de Direito da Universidade de São Paulo, Tese (Doutorado), 2007.

DEGREEF, Hugo Rocha. Presunciones e indicios en juicio penal. 2. ed. Buenos Aires: Ediar, 1997.

DELLEPIANE, Antonio. Nueva teoría de la prueba. 9. ed. 4. reimp. Santa Fe de Bogotá: Temis, 2000.

DEVLIN, Patrick. Trial by Jury. London: Stevens \& Sons Limited, 1966.

DOHRING, Eric. La prueba. Buenos Aires: Valletta, 2003.

DONIGAN, Robert; FISCHER, Edward. The evidence handbook. Evanston: The traffic institute of Northwestern university, 1980.

DOSI, Ettore. Sul principio del libero convincimento del giudice nem processo penale. Universitá di Parma, pubblicazioni della facoltá di giurisprudenza. Milano: Giuffrè, 1957.

DOTTI, René Ariel. Curso de direito penal: parte geral. Rio de Janeiro, Forense, 2001.

ECHANDÍA, Hernando Devis. Compendio de derecho procesal: pruebas judiciales. 10. ed. Medellín: Biblioteca jurídica Diké, 1994, t. II.

Teoria general de la prueba judicial. 2. ed. Buenos Aires: Victor P. De Zavalía, 1972, t. I e II.

FERRAZ JUNIOR, Tércio Sampaio. Introdução ao estudo do direito: técnica, decisão, dominação. $6^{\mathrm{a}}$ ed. São Paulo: Atlas, 2008. 
FERRER BELTRÁN, Jordi. La valoración racional de la prueba. Madrid, Barcelona, Buenos Aires: Marcial Pons, 2007.

FERRAJOLI, Luigi. Direito e Razão: teoria do garantismo penal. Trad. de Ana Paula Zomer, Fauzi Hassan Choukr, Juarez Tavares e Luiz Flavio Gomes. São Paulo: Revista dos Tribunais, 2002.

FERRI, Enrico. Princípios de Direito Criminal. Tradução de Paulo Capitanio. Campinas: Bookseller, 1996.

FIGUEIREDO DIAS, Jorge. Direito Processual Penal. Reimpressão. Coimbra: Coimbra, 2004.

FLORIAN, Eugenio. Delle prove penali. Milano: Dottor Francesco Vallardi, 1921, v. I.

FRANCO, Ary Azevedo. O júri e a Constituição Federal de 1946. Rio de Janeiro, Forense, 1956.

FREDERICO MARQUES, José. A Instituição do Júri. São Paulo: Saraiva, 1963. . Elementos de direito processual penal. Campinas: Millennium, 2003, v.

III.

FORSYTH, William. History of a tryal by jury. Jersey city: Frederick D. Linn \& Company, 1875.

GASCÓN ABELLAN, Marina. Los hechos en el derecho: bases argumentales de la prueba. $3^{\mathrm{a}}$ ed. Madrid, Barcelona e Buenos Aires, 2010.

. Sobre la possibilidad de formular estandares de prueba objetivos.

DOXA: Cuadernos de Filosofía del Derecho. Alicante. n. 28, 2005.

GINESTE, Fernand. Essai sur l'histoire et l'organisation du jury criminal en France et dans les états modernes. Castres: Abeilhou, 1896.

GIORDANI, Mário Curtis. Direito Penal Romano. $2^{\text {a }}$ ed. Rio de Janeiro: Forense, 1987. 
GIUFFRÈ, Vincenzo. La represione criminale nell'esperienza romana. 5. ed. Napoli: Jovene, 1998.

GOLDSCHMIDT, James. Problemas jurídicos y políticos del Proceso Penal. Barcelona: Bosch, 1935.

GOLDSTEIN, Howard W. Grand Jury practice. New York: Law Journal Press, 1998, Item 2.02 .

GOMES, Márcio Schlee. Júri: limites constitucionais da pronúncia. Porto Alegre: Sergio Antonio Fabris editor, 2010.

GOULART, Fabio Rodrigues. Tribunal do Júri: aspectos críticos relacionados à prova. São Paulo: Atlas, 2008.

GRECO FILHO, Vicente. Manual de Processo Penal. $7^{\mathrm{a}}$ ed. São Paulo: Saraiva, 2009.

. Questões polêmicas sobre a pronúncia. Tribunal do Júri: Estudo sobre a mais democrática instituição jurídica brasileira, (Coord. Rogerio Lauria Tucci). São Paulo: Revista dos Tribunais, 1999.

GRECO, Rogério. Curso de direito penal: parte geral. Niterói: Impetus, 2005, v. I.

GRINOVER, Ada Pellegrini; MAGALHÃES GOMES FILHO, Antonio; SCARANCE FERNANDES, Antonio. Recursos no Processo Penal. $5^{\mathrm{a}}$ ed. São Paulo: Revista dos Tribunais, 2007.

HASSEMER, Winfried. Fundamentos del derecho penal. Barcelona: Bosch, 1984.

HÉLIE, Faustin. Traité de l'instruction criminelle. $2^{\mathrm{a}}$. Paris, 1867, n. 2010, v. V.

IACOVIELLO, Francisco Mauro. I criteri de valutazione della prova. La regola del caso: materiali sul ragionamento giurídico. Mario Bessone e Riccardo Guastini (Org). Padova: Cedam, 1995.

IBAÑES, Perfecto Andrés. Valoração da prova e sentença penal. Rio de Janeiro: Lumen Juris, 2006. 
IRIBURE JÚNIOR, Hamilton da Cunha. A pronúncia no procedimento do Tribunal do Júri brasileiro. São Paulo: Pontifícia Universidade Católica de São Paulo, (Tese de Doutorado em Direito), 2009.

KNIJNIK, Danilo. A prova nos juízos cível, penal e tributário. Rio de Janeiro: Forense, 2007.

. Os standards do convencimento judicial: Paradigmas para o seu possível controle. Revista Forense. Rio de Janeiro, n. 353, 2001.

LAUDAN, Larry. Por qué un estandar de prueba subjetivo y ambíguo no es un estandar. DOXA: Cuadernos de Filosofía del Derecho. Alicante. n.28. 2005.

LEONE, Giovanni. Tratado de Derecho Procesal Penal. Tradução de Santiago Sentís Melendo. Buenos Aires: EJEA, 1963, v. I.

LIMA, Eric Alexandre Lavoura. A coisa julgada penal e seus limites objetivos. São Paulo: 2008. Dissertação (Mestrado). Faculdade de Direito da Universidade de São Paulo.

LIMA, Marcellus Polastri. Curso de Processo Penal. 2a ed. Rio de Janeiro: Lumen Juris, 2009, v. III.

LOPES JUNIOR, Aury. Direito Processual Penal e sua conformidade constitucional. $3^{\text {a }}$ ed. Rio de Janeiro: Lumen Juris, 2010, v. II.

. Introdução crítica ao Processo Penal (Fundamentos da Instrumentalidade Garantista). $3^{\mathrm{a}}$ ed. Rio de Janeiro: Lumen Juris, 2005.

LUCA, Giuseppe de. Il sistema delle prove penali e il principio del libero convincimento nel nuovo rito. Rivista Italiana di Diritto e Procedura Penale. Milano. n. 4, 1992.

MACHADO, Antônio Alberto. Curso de Processo Penal. $3^{\mathrm{a}}$ ed. São Paulo: Atlas, 2010.

MAGAlHÃES, GOMES FILHO, Antonio. A motivação das decisões penais. São Paulo: Revista dos Tribunais, 2001.

. Direito à prova no processo penal. São Paulo: Revista dos Tribunais, 1997. 
. Notas sobre a terminologia da prova (reflexos no processo penal brasileiro). Estudos em homenagem à professora Ada Pellegrini Grinover. Org. Flávio Luiz Yarshell e Maurício Zanoide de Moraes. São Paulo: DPJ, 2005.

MAGARINOS TORRES, Antonio Eugenio. Processo penal do júri no Brasil. São Paulo: Quorum, 2008.

MALAN, Diogo Rudge. Direito ao confronto no Processo Penal. Rio de Janeiro: Lumen Juris, 2009.

MALATESTA, Nicola Framarino Dei. A lógica das provas em matéria criminal. Tradução de Alexandre Correia. São Paulo: Saraiva, 1960, v. I.

MANZINI, Vincenzo. Tratado de Derecho Procesal Penal. Tradução de Santiago Sentis Melendo e Marino Ayerra Redín. Buenos Aires: EJEA, 1951.

MARQUES PORTO, Hermínio Alberto. Júri: Procedimentos e aspectos de julgamentos. Questionários. 12ª ed. São Paulo: Saraiva, 2007.

MCCONVILLE, Mike e MILSKY, Chester. Jury trials and plea bargaining: A true history. Oxford and Portland, Oregon: Hart Publishing, 2005.

MÉDICI, Sérgio de Oliveira. Revisão criminal. $2^{\mathrm{a}}$ ed. São Paulo: Revista dos Tribunais, 2000 .

MELENDO, Santiago Sentis. In dubio pro reo. Buenos Aires: EJEA, 1971.

MENDES DE ALMEIDA, Joaquim Canuto. A contrariedade da instrução criminal. São Paulo: Faculdade de Direito da Universidade de São Paulo. Tese (Livre Docência), 1937. . Ação Penal: Análises e Confrontos. São Paulo: Faculdade de Direito da Universidade de São Paulo, Tese (Cátedra), 1938.

MIRABETE, Julio Fabbrini. Processo penal. 18 a ed. São Paulo: Atlas, 2006.

MITTERMAIER, Karl. Tratado de la prueba em matéria criminal. Tradução de Primitivo González del Alba. Buenos Aires: Hammurabi, 2006. 
MONTEIRO, Cristina Líbano. Perigosidade de inimputáveis e in dubio pro reo. Coimbra: Coimbra editora, 1997.

MONTELEONE, Girolamo. Alle origini del principio del libero convincimento del giudice. Rivista di Diritto Processuale. Padova: Cedam. v.63. n.1, genn./febb. 2008.

MOURA, Maria Thereza Rocha de Assis. A prova por indícios no processo penal. Reimpressão. Rio de Janeiro: Lumen Juris, 2009.

NASSIF, Aramis. Júri: instrumento da soberania popular. $2^{\mathrm{a}}$ ed. Porto Alegre: Livraria do Advogado, 2008.

. O novo Júri brasileiro. Porto Alegre: Livraria do Advogado, 2009.

NETO, Eduardo Diniz. Do parnaso aos trópicos: origem e evolução do tribunal do júri. Revista de Direito Público da Universidade Estadual de Londrina. Londrina, Ano 1, ed. n. 3, 2006.

NOBILI, Massimo. Il principio del libero convincimento del giudice. Milano: Giuffré, 1974.

NUCCI, Guilherme de Souza. Júri: Princípios constitucionais. São Paulo: Juarez de Oliveira, 1999. . Tribunal do Júri. São Paulo: Revista dos Tribunais, 2008.

NUVOLONE, Pietro. Contributo Alla teoria dela sentenza instruttoria penale. Padova: Cedam, 1969.

OLIVEIRA, Eugênio Pacelli de. Curso de Processo Penal. 15ª ed. Rio de Janeiro: Lumen Juris, 2011.

. Curso de Processo Penal. 10 a ed. Rio de Janeiro: Lumen Juris, 2008.

ORTEGO PÉREZ, Francisco. El juicio de acusación. Barcelona: Atelier, 2008. 
PATTI, Salvatore. Libero convincimento e valutazione delle prove. Rivista di Diritto Processuale. Padova: Cedam. V. 40, n. 3, lug./sett, 1985.

PEREIRA E SOUSA, Joaquim José Caetano. Primeiras linhas sobre o processo criminal. $4^{\mathrm{a}}$ ed., Lisboa: Impressão Regia, 1831.

PIMENTA BUENO, José Antonio. Apontamentos sobre o processo criminal brasileiro. $2^{\mathrm{a}}$ ed. Rio de Janeiro: Empreza Nacional do Diário, 1857.

Apontamentos sobre o processo criminal pelo jury. Rio de Janeiro, Typ imperial e constitucional de J. Villeneuve, 1849.

PINHO, Ana Cláudia Bastos de; GOMES, Marcus Alan de Melo. Impronúncia: Uma nódoa inquisitiva no Processo Penal brasileiro. Ciências Criminais: Articulações críticas em torno dos 20 anos da Constituição da República. (Coord. Ana Cláudia Bastos de Pinho e Marcus Alan de Melo Gomes). Rio de Janeiro: Lumen Juris, 2008.

PITOMBO, Sérgio Marcos de Moraes. Pronúncia e in dubio pro societate. Revista da Escola Paulista da Magistratura, ano 4, $\mathrm{n}^{\circ}$ 1. São Paulo: Imprensa oficial do Estado de São Paulo, 2003.

PROFFATT, John. A treatise on trial by jury. San Francisco: Sumner Whitney and company, 1877.

QUEIJO, Maria Elizabeth. Da revisão criminal: condições da ação. São Paulo: Malheiros, 1998.

RANGEL, Paulo. Direito Processual Penal. 16ª ed. Rio de Janeiro: Lumen Juris, 2009.

. Direito Processual Penal. 10 a ed. Rio de Janeiro: Lumen Juris, 2005.

. Tribunal do Júri: Visão lingüística, histórica, social e dogmática. Rio de Janeiro: Lumen Juris, 2007.

ROXIN, Claus. Derecho Procesal Penal. Tradução de Julio Maier. Buenos Aires: Editores del peurto, 2000. 
SALAVERRIA. Juan Igartua. Valoración de la prueba, motivación y control em el proceso penal. Valencia: Tirant lo blanch, 1995.

SAMMARCO, Angelo Alessandro. Metodo probatório e modelli de ragionamento nel processo penale. Milano: Giuffrè, 2001.

SANTALUCIA, Bernardo. Diritto e processo penale nell'antica Roma. 2. ed. Milano: Giuffrè, 1998.

SANTOS, Juarez Cirino dos. Direito penal: parte geral. $2^{\mathrm{a}}$ ed. Curitiba: ICPC; Lumen Juris, 2007.

SCAPINI, Nevio. La prova per indizi nel vigente sistema del processo penale. Milano: Giuffrè, 2001.

SCARANCE FERNANDES, Antonio. Processo penal constitucional. $6^{\text {a }}$ ed. São Paulo: Revista dos Tribunais, 2010.

SCHITTAR, Domenico Carponi. Al di lá del Ragionevole dubbio e oltre: Um tentativo di chiarezza sui principi. Milano: Giuffrè, 2008.

SILVEIRA, Daniel. Prova, argumento e decisão: critérios de suficiência para orientação dos juízos de fato no direito processual brasileiro. São Paulo: Dissertação (Mestrado). Faculdade de Direito da Universidade de São Paulo, 2011.

SIQUEIRA, Galdino. Curso de Processo Criminal. $2^{\text {a }}$ ed. São Paulo: Livraria Magalhães, 1937.

STELLA, Frederico; GALAVOTTI, Maria Carla. L'oltre il ragionevole dubbio come standard probatorio - Le infondate divagazioni dell'espistemolog Laudan. Rivista Italiana de Diritto e Procedura Penale. v. 48, fasc. 3, Milano, 2005.

STRECK, Lenio Luiz. Tribunal do Júri: símbolos e rituais. $3^{\mathrm{a}}$ ed. Porto Alegre: Livraria do Advogado, 1998.

TARUFFO, Michele. La semplice veritá: o giudice e la construzione dei fatti. Bari: Laterza, 2009. 
. La prueba de los hechos. Tradução de Jordi Ferrer Beltrán. $4^{\mathrm{a}}$ ed. Trotta:

Madrid, 2011.

. Rethinking the Standards of Proof. The American journal of comparative law, HeinOlnine, $\mathrm{n}^{\mathrm{o}}$ 51, 2003.

. Conocimiento científico y criterios de la prueba judicial. Proceso, prueba y estándar. Santiago Ortega Gomero (editor). Lima: Aras, 2009.

. Tres observaciones sobre: por qué un estándar de prueba subjetivo y ambíguo no es un estandar: de Larry Laudan. DOXA: Cuadernos de Filosofía del Derecho, n. 28. Alicante, 2005.

TONINI, Paolo. A prova no processo penal italiano. Tradução da 4. edição italiana de Alexandra Martins e Daniela Mróz. São Paulo: Revista dos Tribunais, 2002.

TORNAGHI, Hélio. Instituições de Processo Penal. $2^{a}$ ed. São Paulo: Saraiva, 1977, v. I e IV.

TORRES, José Henrique Rodrigues. Quesitação: a importância da narrativa do fato na imputação inicial, na pronúncia, no libelo e nos quesitos. Tribunal do Júri: estudo sobre a mais democrática instituição jurídica brasileira. Coordenação de Rogério Lauria Tucci. São Paulo: Revista dos Tribunais, 1999.

TORRES, Nelson Bassatt. La duda razonable en la prueba penal. Bilbao: Universidad del País Vasco editorial, 2007.

TOURINHO FILHO, Fernando da Costa. Processo Penal. $27^{\mathrm{a}}$ ed. São Paulo: Saraiva, 2005.

TRICKETT, William. Preponderance of evidence and reasonable doubt. The Forum, n. 4, vol. X, 1906.

TUBENCHLAK, James. Tribunal do Júri: Contradições e soluções. $4^{\mathrm{a}}$ ed. São Paulo: Saraiva, 1994. 
TUCCI, Rogério Lauria. Lineamentos do processo penal romano. São Paulo: José Bushatsky, 1976.

. Direitos e garantias individuais no processo penal brasileiro. $3^{a}$ ed. São Paulo: Revista dos Tribunais, 2009.

VARELA, Casimiro A. Valoración de la prueba. $2^{\mathrm{a}}$ ed. Buenos Aires: Astrea, 1999.

VARS, Fredrick. Toward a general theory of standards of proof. Catholic University Law review, 60 Catholic Univ. L. Rev. 1, Washington DC, 2010.

WALTER, Gerhard. Libre apreciación de la prueba. Bogotá: Temis, 1985.

WATANABE, Kazuo. Da cognição no processo civil. $3^{\mathrm{a}}$ ed. São Paulo: Perfil, 2005.

ZANGARI, Mario, Natureza jurídica da Pronúncia. São Paulo: Faculdade de Direito da Universidade de São Paulo, Dissertação (Livre-Docência), 1953.

ZANOIDE DE MORAES, Maurício. Presunção de inocência no processo penal brasileiro: análise de sua estrutura normativa para a elaboração legislativa e para a decisão judicial. Rio de Janeiro: Lumen Juris, 2010.

ZAPPALÁ, Amália Gomes. A Pronúncia em um sistema de garantias. São Paulo: Faculdade de Direito da Universidade de São Paulo, Tese (Doutorado), 2004.

Apreciação judicial da resposta à acusação no procedimento do júri.

Boletim IBCCRIM: São Paulo, ano 17, n. 201, pp. 14/15, ago. 2009.

ZAZA, Carlo. Il ragionevole dubbio nella lógica della prova penale. Giuffrè: Milano, 2008.

\section{DICIONÁRIOS}

BERGER, Adolf. Encyclopedic dictionary of Roman Law. Philadelphia: The American Philosophical society, 1991. 
LOYN, H.R. Dicionário da Idade Média. Rio de Janeiro: Jorge Zahar, 1997.

Dicionário escolar da língua portuguesa/Academia Brasileira de Letras. $2^{\mathrm{a}}$ ed. São Paulo: Companhia Editora Nacional, 2008. 